\title{
Low-cost Arduino-based Temperature Measuring System
}

\author{
Pacheco Nazareno de Oliveira ${ }^{1}$, Batista Giovani ${ }^{2}$, Estuqui Anderson Fontes ${ }^{1}$ e Silva Lucas da ${ }^{1}$ \\ 1 Research and Master, University Center Sociesc - UniSociesc, Street Albano Schmidt, 3333, Boa Vista, \\ Joinville, Santa Catarina, Brazil; nazareno.pacheco@gmail.com; \\ 1 Student of Control Engineering and Automation University Center Sociesc - UniSociesc, Street Albano \\ Schmidt, 3333, Boa Vista, Joinville, Santa Catarina, Brazil; andersonfontes10@hotmail.com; \\ 1.s.sfs@hotmail.com. \\ 2 Federal Institute of Santa Catarina, Street dos Imigrantes, 445, Rau, Jaraguá do Sul, Santa Catarina, Brazil; \\ giovani_batista@hotmail.com.br \\ * Correspondence: nazareno.pacheco@gmail.com; Tel.: +55-47-3461-0277
}

\begin{abstract}
The commercial equipment that carries out the measurement of temperature has a high cost. Therefore, this article describes the development of a temperature measurement equipment, which uses a microcontrolled platform, responsible for managing the data of the collected temperature signals and making available the acquired information, so that they can be verified in real time at the measurement site, or remotely. The construction of the temperature measurement equipment was performed using open platform hardware / software, where performance tests were carried out with the objective of developing a temperature measurement equipment that has measurement quality and low cost.
\end{abstract}

Keywords: Open microcontrolled platform; Data acquisition; Remote measurement.

\section{Introduction}

Automatic test and measurement (or data acquisition) [1][2] systems are used to experimentally evaluate the parameter values of a process, product or experiment. They are different from monitoring systems integrated in process / plant supervision / control because the measured values are not used directly (ie as part of the same system) to automatically adjust the process / plant under test [3]. At an industrial level, increased automation in the production process increasingly amplifies the needs for accurate measurement systems for quality control and, consequently, the need for software development. At the scientific level, similarly new experiments and machines (such as particle accelerators, astro-telescopes, or space missions) require an impressive performance of automatic measurements and systems, often beyond the limits of the latest generation [4].

This approach promises access to low-cost sensor-based instrumentation by resource-poor researchers, underdeveloped and developing world laboratories. Historically data acquisition systems have a high cost, both for small and medium companies, as for the academy [5]. This article provides a methodology for applying an open source approach to designing and developing a low cost temperature acquisition system that allows data from the monitored process to be accessed remotely.

As an additional resource, because the acquisition system has a remote communication interface, it meets the most current in the industry, called industry 4.0, or interconnected industry, whereby equipment and operator interact using communication resources via the network of data, also called IoT (Internet of Things) [6][7], which Ray [8]defines as a platform where every day the equipment and processes become smarter, and every day the communication becomes informative. The IoT architecture can be treated as a system that can be physical, virtual, or a joint of the two, which consists of the use of numerous devices such as sensors, actuators, cloud services, communication protocols, developers, etc. This feature stands out in a measuring equipment because providing real- 
time temperature information assists the operator of the machine whose equipment is installed in decision-making.

Recent work shows that the costs of scientific equipment can be dramatically reduced by applying open source principles to your project using a combination of the open source Arduino electronics prototyping platform as described in section 2.

\section{Related work}

Recent work has shown that the costs of a scientific equipment can be dramatically reduced by applying open source principles to your project using the hardware and software combination of the electronic prototyping platform called "Arduino"[9]. Algumas pesquisas fazem uso desta plataforma, podendo-se citar: Fatehnia et al., [10], Mesas-Carrascosa et al., [11], Ali et al., [12], Kviesis e Zacepins [13], Fezary et al., [14], Laskar et al., [15], Groener et al., [16], Prima et al.,[17], Georgieva et al., [18], Gosai e Bhavsar [19] e Pocero et al., [20].

Fatehnia et al., described an automatic double-ring infiltrater system using the Arduino platform, using hall and water level sensors to perform the measurements. The measurements are validated in relation to existing systems, and the collected data is stored in SD card.

Mesas-Carrascosa et al., used the Arduino platform to ensure best agricultural practices, obtaining real-time information on temperature, air and soil moisture. The system uses the information collected and previously processed in relation to performance models to monitor the crop, and can be accessed remotely through a mobile application.

Ali et al., described a project using the Arduino platform to measure and record data indoors. The system uses several sensors to measure temperature, air humidity, light intensity, $\mathrm{CO}_{2}$ concentrations, voltage, differential pressure and human occupancy of the environment. From the data collected, a research is carried out to investigate the parameters that influence the quality of life in these environments.

Kviesis e Zacepins carried out the monitoring of bee colonies through the acquisition of temperature, humidity and beehive weight signals. All information is obtained and processed using the Arduino platform, assisting in the work of precision beekeeping.

Fezary et al., developed a human health monitoring system, using the data of heart rate, body temperature and blood pressure as the analysis data. The collected data are processed and sent remotely through the Arduino platform to health care providers, allowing the verification and monitoring of the patient's health status.

Laskar et al., used the Arduino platform to design a meteorological system, providing information about the climate, being monitored the temperature, humidity and air pressure.

Groener et al., have described a preliminary design of a low-cost greenhouse that uses the Arduino platform and has the potential to contribute to food security in countries where the average income of the population is low. The code implemented on the platform and the greenhouse structure are designed for crops such as tomatoes, peppers and onions.

Prima et al., proposed the creation of a laboratory kit using the Arduino platform and sensors to improve quality in science education. The proposed system consists of investigating heat transfer and temperature changes at certain positions along a rod when it is being heated.

Georgieva et al., used the Arduino platform for a soil quality parameter monitoring project with wireless communication and using the concept of modular systems to carry out measurements of temperature, humidity, conductivity and soil acidity.

Gosai e Bhavsar performed the acquisition of temperature data using the Arduino platform to verify the influence of temperature on the life of a cutting tool. According to the obtained data, modifications are made in the cutting parameters, aiming at the best use of the tool.

Pocero et al., have structured a real-time monitoring of several school buildings with the objective of improving energy efficiency. The system uses the Arduino platform to monitor and manage temperature, humidity, presence, noise level and energy consumption signals. 
As verified in the cited examples, the Arduino platform is widely used in the most diverse types of research, aiding in the process of data acquisition and processing.

\section{Experimental Section}

The following materials were used to assemble the measuring equipment: one Arduino Mega board (Figure 1a), three K-type thermocouples (Figure 1b), three thermocouple modules (Figure 1c), a real-time clock module (Figure 1d ), a data storage module (Figure 1e), a micro SD card, a network communication module (Figure 1f), and a base board module L (Figure 1g) to interconnect all modules to the Arduino Mega board.

Figure 1. Materials used in the construction and testing of measuring equipment.

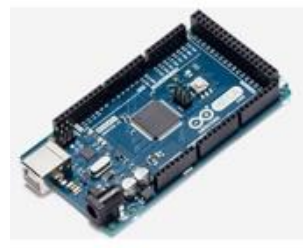

(a)

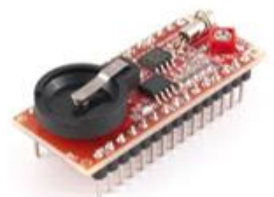

(d)

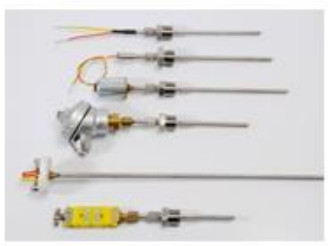

(b)

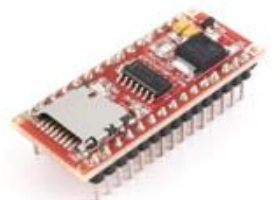

(e)

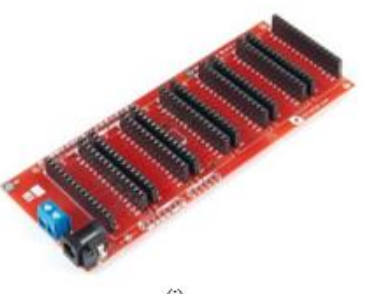

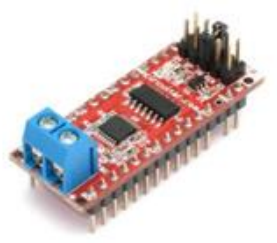

(c)

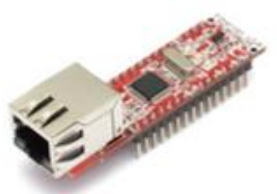

(f)

To explain the assembly of the equipment of the temperature measurement equipment, Figure 2 will be used as a reference, indicating the function of each component as well as the reason for the connection between them.

Figure 2. Temperature measuring equipment. 


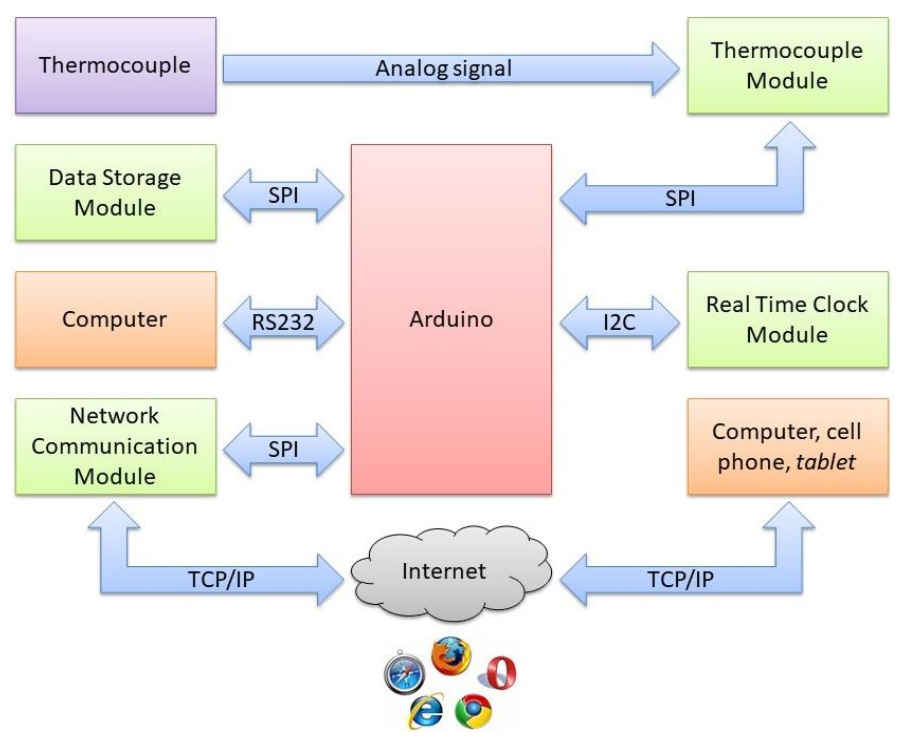

Using the temperature signal as the starting point, the temperature measuring equipment uses type $\mathrm{K}$ thermocouples to acquire the temperature signals in the mold, and are then transmitted analogously to the thermocouple module.

In the thermocouple module, the signal is amplified, followed by a signal filtering process to reduce noise and interference, thus improving the quality of the measurement. In the same module is realized the cold joint compensation, as well as the conversion of the signal to the digital format, which is the format of data that digital systems can operate. As a result, the thermocouple module data is sent serially to the Arduino Mega board.

The process mentioned so far is the acquisition, processing, conversion and sending of the signal to the Arduino Mega board. However, in order for the signal to be used in the creation of graphs and spreadsheets, the signal is acquired, so the real time clock module is used to provide the precise measurement time, which keeps running even during power outages, as there is a reserve power system using battery.

Due to the speed of acquisition of the temperature signals in the mold and the measurement time information, the internal memory of the Arduino Mega board would run out quickly. Therefore, the information acquired by the temperature measuring equipment is recorded on an SD card through the data storage module, which facilitates and makes available the transfer and analysis of data in other equipment only by removing the card.

The network communication module accesses the information acquired by the temperature measurement equipment and sends the data remotely to other equipment connected in the network, such as: computer, cellular, tablet. As a design feature, considering class C IP addresses, where the first three octets are reserved for network addressing, up to 254 measurement and control equipment can be interconnected. Therefore, the possibility of forming a distributed measurement system is created.

In order to carry out the programming of the processes inherent to a temperature measurement equipment, the Arduino software [9] was used and a computer physically connected by means of a USB cable on the Arduino Mega board, which also allows the monitoring of the measurement process of the temperature signals locally.

Figure 3 shows the flowchart used in the programming logic of the temperature measurement equipment, where the internal processes performed by the Arduino Mega board together with the peripherals (modules, sensors and SD card) are available. 
Figure 3. Flow chart of the measurement system.

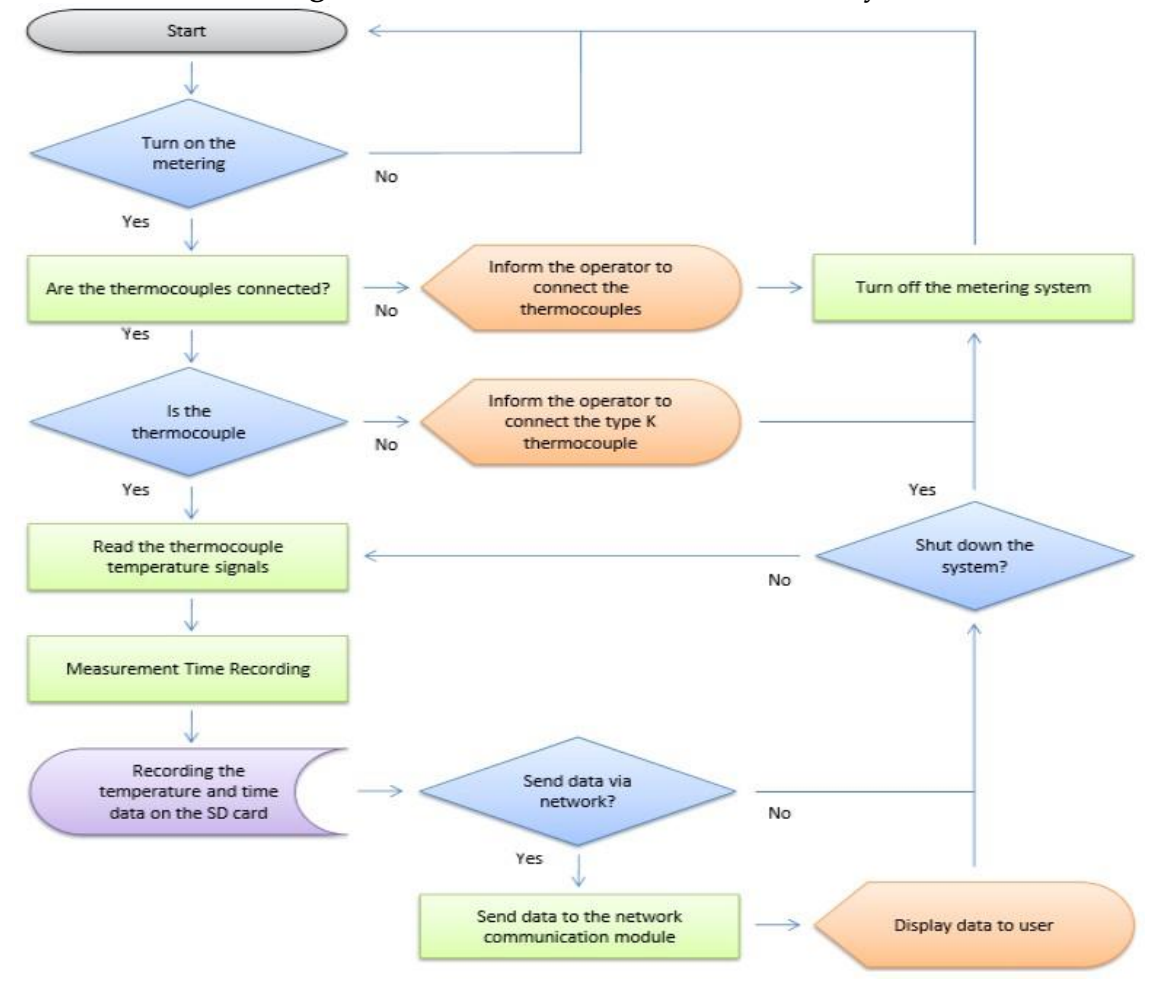

\section{Results and discussion}

To evaluate the performance of the temperature measurement equipment developed in this research, a comparison was made between the temperature signals acquired in relation to the commercial Agilent brand data acquisition system model 34970A (Figure 4a). However, in order to avoid the influence of the K-type thermocouple error in the process of comparing the temperature values, the same thermocouple was used for both the temperature measurement equipment constructed in this research and the Agilent commercial equipment.

Therefore, the Visomes BC200 model was used, as shown in Figure 4d, where the thermostatic bath test was performed, the K-type thermocouple being immersed in an electronically controlled heated liquid solution, thus same temperature measurement medium in the test.

To verify the temperature variation in the heated oil, a $61 / 2$-digit precision Fluke Model 8846A multimeter (Figure $4 \mathrm{~b}$ ) was used in conjunction with a PT100 thermistor with 4-wire connection. In Figure $4 \mathrm{c}$ the test assembly is visualized and all equipment used can be checked. 
Figura 4. Performance verification test of the measurement equipment developed in the research. (a) Data acquisition system; (b) precision multimeter; (c) thermostatic bath test; (d) Thermostatic bath equipment.

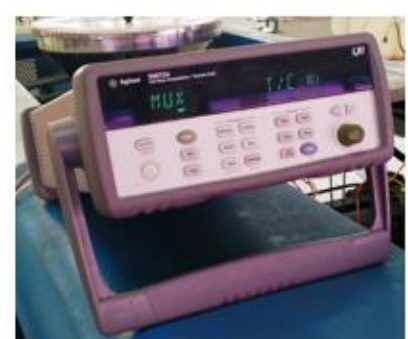

(a)

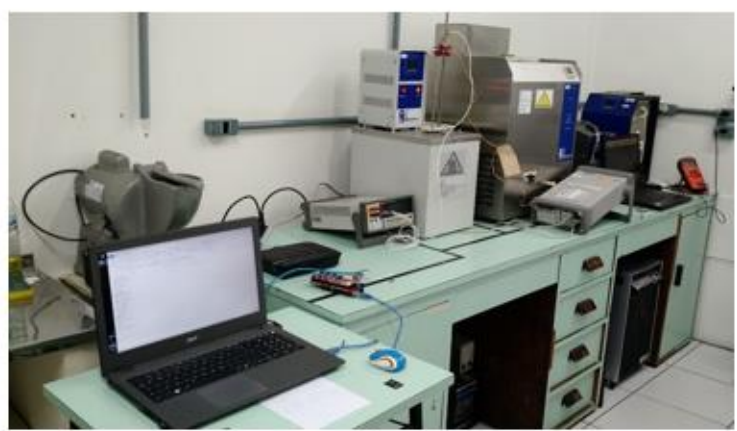

(c)

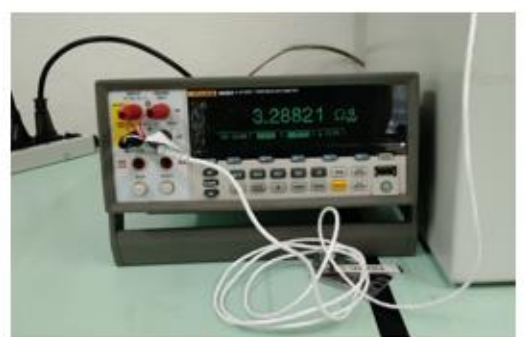

(b)

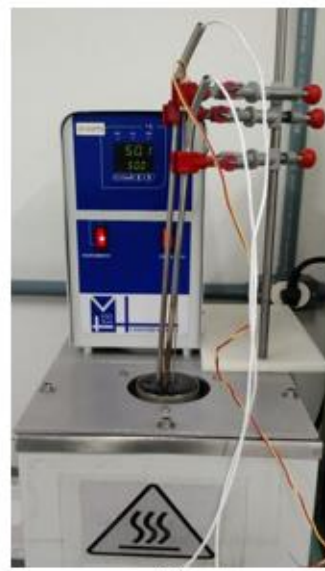

(d)

In relation to the test, three reference temperatures of $50^{\circ} \mathrm{C}, 70^{\circ} \mathrm{C}$ and $90^{\circ} \mathrm{C}$ were used, and the following procedure was performed:

- Temperature measurement using Fluke's precision thermoresistance and multimeter at the beginning, middle, and end of the test to check for possible variations in the temperature of the thermostatic bath oil.

- Individual and sequential measurement of the three channels of the temperature measurement equipment developed in this research together with the K-type thermocouple.

- Temperature measurement using Agilent commercial equipment in conjunction with Type K thermocouple.

In Table 1, the resistance values of the PT100 thermoresistor measured by the Fluke multimeter can be checked and in table 2 the values in Table 1 converted to degrees Celsius.

Table 1. Resistance values measured by the Fluke Precision Multimeter Model 8846A.

\begin{tabular}{|c|c|c|c|c|c|}
\hline \multicolumn{6}{|c|}{ Measurement of the oil temperature in the thermostatic bath test } \\
\hline \multirow{2}{*}{$\begin{array}{c}\text { Oil } \\
\text { temperature } \\
\text { set in Visomes } \\
\text { model BC200 } \\
\text { equipment }\end{array}$} & \multirow{2}{*}{$\begin{array}{l}\text { Time of the test } \\
\text { in which the } \\
\text { acquisition of the } \\
\text { temperature } \\
\text { signal }\end{array}$} & \multicolumn{3}{|c|}{$\begin{array}{l}\text { Temperature measuring equipment } \\
\text { developed in the research }\end{array}$} & \multirow{2}{*}{$\begin{array}{c}\text { Agilent Model } \\
\text { 34970A } \\
\text { Equipment } \\
(\Omega)\end{array}$} \\
\hline & & $\begin{array}{c}\text { Channel } 1 \\
(\Omega)\end{array}$ & $\begin{array}{c}\text { Channel } 2 \\
(\Omega)\end{array}$ & $\begin{array}{c}\text { Channel } 3 \\
(\Omega)\end{array}$ & \\
\hline \multirow{3}{*}{$50^{\circ} \mathrm{C}$} & Start & 119,491 & 119,498 & 119,496 & 119,497 \\
\hline & Medium & 119,490 & 119,497 & 119,497 & 119,498 \\
\hline & End & 119,494 & 119,497 & 119,496 & 119,497 \\
\hline $70^{\circ} \mathrm{C}$ & Start & 127,177 & 127,182 & 127,180 & 127,143 \\
\hline
\end{tabular}




\begin{tabular}{c|c|c|c|c|c}
\hline & Medium & 127,178 & 127,180 & 127,175 & 127,164 \\
\cline { 2 - 5 } & End & 127,180 & 127,184 & 127,174 & 127,164 \\
\hline \multirow{3}{*}{$90^{\circ} \mathbf{C}$} & Start & 134,793 & 134,815 & 134,809 & 134,795 \\
\cline { 2 - 6 } & Medium & 134,812 & 134,817 & 134,816 & 134,816 \\
\cline { 2 - 6 } & End & 134,817 & 134,814 & 134,823 & 134,792 \\
\hline
\end{tabular}

Table 2. Conversion of resistance values measured by Fluke Model 8846A Precision Multimeter in degrees Celsius.

\begin{tabular}{|c|c|c|c|c|c|}
\hline \multicolumn{6}{|c|}{ Measurement of the oil temperature in the thermostatic bath test } \\
\hline \multirow{2}{*}{$\begin{array}{c}\text { Oil } \\
\text { temperature } \\
\text { set in Visomes } \\
\text { model BC200 } \\
\text { equipment }\end{array}$} & \multirow{2}{*}{$\begin{array}{l}\text { Time of the test } \\
\text { in which the } \\
\text { acquisition of the } \\
\text { temperature } \\
\text { signal }\end{array}$} & \multicolumn{3}{|c|}{$\begin{array}{c}\text { Temperature measuring equipment } \\
\text { developed in the research }\end{array}$} & \multirow{2}{*}{$\begin{array}{c}\text { Agilent Model } \\
34970 \mathrm{~A} \\
\text { Equipment } \\
\left({ }^{\circ} \mathrm{C}\right)\end{array}$} \\
\hline & & $\begin{array}{c}\text { Channel } 1 \\
\left({ }^{\circ} \mathrm{C}\right)\end{array}$ & $\begin{array}{c}\text { Channel } 2 \\
\left({ }^{\circ} \mathrm{C}\right)\end{array}$ & $\begin{array}{c}\text { Channel } 3 \\
\left({ }^{\circ} \mathrm{C}\right)\end{array}$ & \\
\hline \multirow{3}{*}{$50^{\circ} \mathrm{C}$} & Start & 50,244 & 50,262 & 50,257 & 50,260 \\
\hline & Medium & 50,242 & 50,260 & 50,260 & 50,262 \\
\hline & End & 50,252 & 50,260 & 50,257 & 50,260 \\
\hline \multirow{3}{*}{$70^{\circ} \mathrm{C}$} & Start & 70,267 & 70,280 & 70,274 & 70,178 \\
\hline & Medium & 70,269 & 70,274 & 70,261 & 70,233 \\
\hline & End & 70,274 & 70,285 & 70,259 & 70,233 \\
\hline \multirow{3}{*}{$90^{\circ} \mathrm{C}$} & Start & 90,227 & 90,285 & 90,269 & 90,232 \\
\hline & Medium & 90,277 & 90,290 & 90,287 & 90,287 \\
\hline & End & 90,290 & 90,282 & 90,306 & 90,224 \\
\hline
\end{tabular}

Analyzing Table 2, during the test period of the thermostatic bath, it was verified that the oil presented low temperature variation, as highlighted in yellow. The maximum variations shown are: $0.020^{\circ} \mathrm{C}$ in the $50^{\circ} \mathrm{C}$ test; $0.107^{\circ} \mathrm{C}$ in the $70^{\circ} \mathrm{C}$ and $0.082^{\circ} \mathrm{C}$ in the $90^{\circ} \mathrm{C}$ assay. Therefore, considered to be stable for the comparative test between the temperature measurement equipment developed in this research and Agilent commercial equipment.

In Table 3 the data of 570 temperature measurements performed during the thermostatic bath test were compiled, where the performance of the temperature measurement equipment developed in this research in relation to commercial Agilent equipment can be verified.

Table 3. Results of the temperature measurement test in the thermostatic bath.

\begin{tabular}{|c|c|c|c|c|c|}
\hline \multirow{3}{*}{$\begin{array}{c}\text { Measurement } \\
\text { reference }\end{array}$} & \multirow{3}{*}{$\begin{array}{l}\text { Measured } \\
\text { values }\end{array}$} & \multicolumn{3}{|c|}{$\begin{array}{c}\text { Temperature measuring equipment } \\
\text { developed in the research }\end{array}$} & \multirow{3}{*}{$\begin{array}{c}\text { Agilent Model } \\
\text { 34970A Equipmen } \\
{ }^{\circ} \mathrm{C}\end{array}$} \\
\hline & & Channel 1 & Channel 2 & Channel 3 & \\
\hline & & ${ }^{\circ} \mathrm{C}$ & ${ }^{\circ} \mathrm{C}$ & ${ }^{\circ} \mathrm{C}$ & \\
\hline \multirow{4}{*}{$50^{\circ} \mathrm{C}$} & Medium & 46,90 & 47,50 & 47,12 & 48,742 \\
\hline & Minimum & 46,50 & 47,00 & 46,75 & 48,662 \\
\hline & Maximum & 47,25 & 47,75 & 47,75 & 48,826 \\
\hline & Amplitude & 0,75 & 0,75 & 1,00 & 0,164 \\
\hline $70^{\circ} \mathrm{C}$ & Medium & 66,65 & 67,17 & 66,93 & 68,390 \\
\hline
\end{tabular}




\begin{tabular}{l|c|c|c|c|c} 
& Minimum & 66,25 & 66,75 & 66,50 & 68,264 \\
\cline { 2 - 6 } & Maximum & 67,00 & 67,50 & 67,50 & 68,488 \\
\cline { 2 - 6 } & Amplitude & 0,75 & 0,75 & 1,00 & 0,224 \\
\hline \multirow{4}{*}{$\mathbf{9 0}^{\circ} \mathbf{C}$} & Medium & 87,25 & 87,54 & 87,53 & 88,304 \\
\cline { 2 - 6 } & Minimum & 87,00 & 87,25 & 87,25 & 88,261 \\
\cline { 2 - 6 } & Maximum & 87,50 & 87,75 & 87,75 & 88,439 \\
\cline { 2 - 6 } & Amplitude & 0,50 & 0,50 & 0,50 & 0,178 \\
\hline
\end{tabular}

As a result, with respect to the worst values recorded statistically, it can be stated with $95 \%$ confidence that the maximum variation (or amplitude) of the measured temperature in the channels is $0.0305^{\circ} \mathrm{C}$, highlighted in yellow in Table 4 . Soon, considerably lower than the value of $1.00{ }^{\circ} \mathrm{C}$ seen in Table 3, evidencing the quality of measurement of the temperature measurement equipment developed in this research.

Regarding the average temperature value, taking the Agilent commercial measuring equipment as a reference, considering the worst values recorded, statistically, it can be stated with $95 \%$ confidence that the maximum variation of the average temperature between equipment is between the values of -1.85152 and $-1.82294^{\circ} \mathrm{C}$, with an average value of $-1.83723^{\circ} \mathrm{C}$, highlighted in green in Table 5, which corroborates the mean value calculated from Table 3, highlighted in green, of $1,84^{\circ}$ C.

Table 4. Statistical analysis of test data for validation of temperature measuring equipment temperature variation in measuring channels

\begin{tabular}{|c|c|c|c|c|c|c|c|}
\hline \multirow[t]{2}{*}{$\begin{array}{c}\text { Measurement } \\
\text { reference }\end{array}$} & \multirow{2}{*}{\begin{tabular}{|l|} 
Data source \\
Channel 1 \\
\end{tabular}} & \multirow{2}{*}{$\begin{array}{c}\text { Mean }\left({ }^{\circ} \mathrm{C}\right) \\
46,9048 \\
\end{array}$} & \multirow{2}{*}{$\begin{array}{c}\begin{array}{c}\text { Standard } \\
\text { deviation } \\
\left({ }^{\circ} \mathrm{C}\right)\end{array} \\
0,1711 \\
\end{array}$} & \multicolumn{3}{|c|}{$\begin{array}{c}95 \% \text { Confidence Interval } \\
\text { for Measured } \\
\text { Temperature }\left({ }^{\circ} \mathrm{C}\right) \\
\end{array}$} & \multirow{2}{*}{$\begin{array}{c}\begin{array}{c}\text { Range of } \\
\text { confidence } \\
\text { interval }\left({ }^{\circ} \mathrm{C}\right)\end{array} \\
0,0281 \\
\end{array}$} \\
\hline & & & & 46,8908 & $\sim$ & 46,9189 & \\
\hline \multirow{3}{*}{$50^{\circ} \mathrm{C}$} & Channel 2 & 47,5048 & 0,1640 & 47,4913 & $\sim$ & 47,5183 & 0,0270 \\
\hline & Channel 3 & 47,1189 & 0,1852 & 47,1036 & $\sim$ & 47,1341 & 0,0305 \\
\hline & Agilent & 48,7421 & 0,0304 & 48,7396 & $\sim$ & 48,7446 & 0,0050 \\
\hline \multirow{4}{*}{$70^{\circ} \mathrm{C}$} & Channel 1 & 66,6513 & 0,1527 & 66,6388 & $\sim$ & 66,6639 & 0,0251 \\
\hline & Channel 2 & 67,1662 & 0,1719 & 67,1521 & $\sim$ & 67,1804 & 0,0283 \\
\hline & Channel 3 & 66,9342 & 0,1805 & 66,9194 & $\sim$ & 66,9491 & 0,0297 \\
\hline & Agilent & 68,3900 & 0,0439 & 68,3834 & $\sim$ & 68,3936 & 0,0102 \\
\hline \multirow{4}{*}{$90^{\circ} \mathrm{C}$} & Channel 1 & 87,2539 & 0,1208 & 87,2440 & $\sim$ & 87,2639 & 0,0199 \\
\hline & Channel 2 & 87,5364 & 0,1579 & 87,5234 & $\sim$ & 87,5494 & 0,0260 \\
\hline & Channel 3 & 87,5289 & 0,1577 & 87,5160 & $\sim$ & 87,5419 & 0,0259 \\
\hline & Agilent & 88,3038 & 0,0309 & 88,3013 & $\sim$ & 88,3064 & 0,0051 \\
\hline
\end{tabular}

As a result, with respect to the worst values recorded statistically, it can be stated with $95 \%$ confidence that the maximum variation (or amplitude) of the measured temperature in the channels is $0.0305^{\circ} \mathrm{C}$, highlighted in yellow in Table 4 . Soon, considerably lower than the value of $1.00^{\circ} \mathrm{C}$ seen in Table 3, evidencing the quality of measurement of the temperature measurement equipment developed in this research.

Regarding the average temperature value, taking the Agilent commercial measuring equipment as a reference, considering the worst values recorded, statistically, it can be stated with $95 \%$ confidence that the maximum variation of the average temperature between equipment is between the values of -1.85152 and $-1.82294^{\circ} \mathrm{C}$, with an average value of $-1.83723^{\circ} \mathrm{C}$, highlighted in green in 
Table 5, which corroborates the mean value calculated from Table 3, highlighted in green, of $1,84^{\circ}$ C.

Table 5. Statistical analysis of test data for validation of temperature measuring equipment temperature variation in measuring channels.

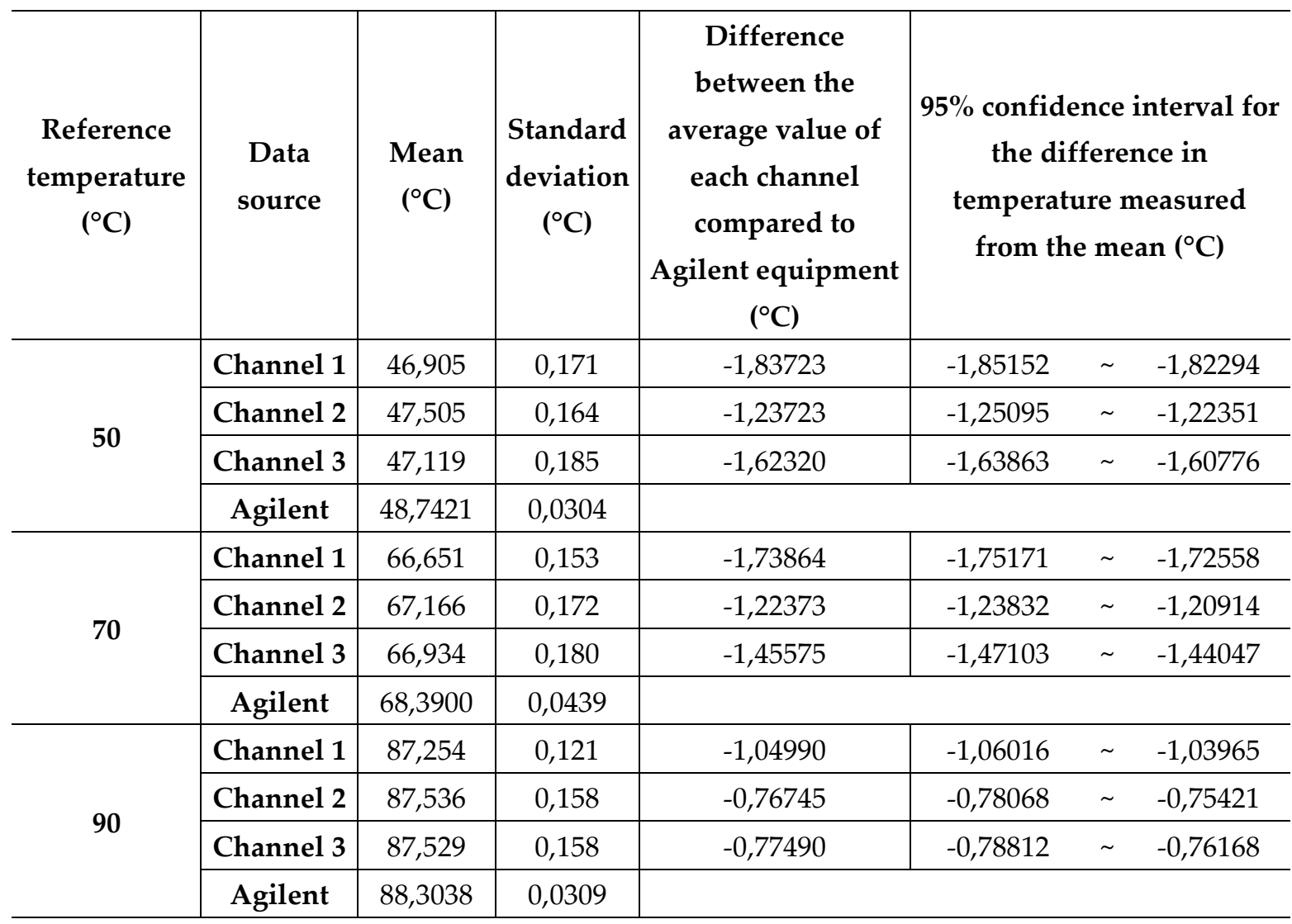

To verify the operation of the temperature measurement equipment developed in this research in the measurement of temperature signals in the mold of polymer injection machines, an experiment was carried out using the Sandretto model 50/247 polymer injection molding machine and a mold of P20 steel.

In the test, the following procedures were adopted: the machine starts the process of injection of polymeric material into the mold, generating several pieces, as shown in Figure 5a, until the system acquires thermal stability, being monitored through the thermocouples inserted in the together with Agilent's temperature acquisition system, as highlighted in red in Figure $5 b$. Soon after, with the system operating in a stable way, the temperature in the mold is acquired. 
Figure 5. (a) Parts injected into the Sandretto polymer injection molding machine; (b) Measuring mold temperature using Agilent equipment.

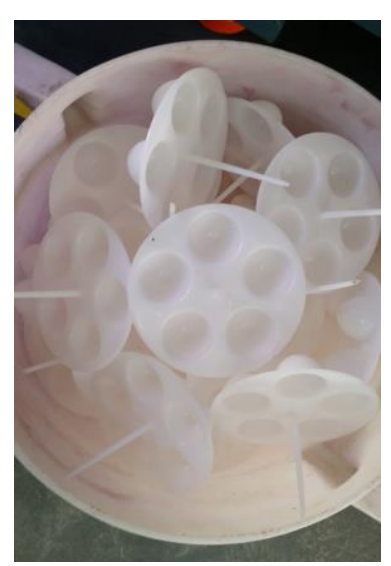

(a)

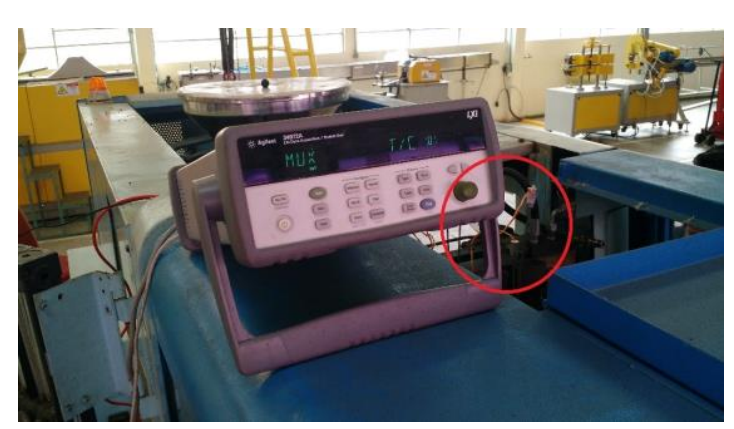

(b)

As a result of the test, it was verified that the equipment developed in the research operated in a stable manner, as seen in the graph of Figure 6, measuring the temperature in the mold without presenting oscillations or measurement noises, however, it presented a measurement error, within the expected, as seen in Table 4 and Table 5.

Figure 6. Mold temperature values.

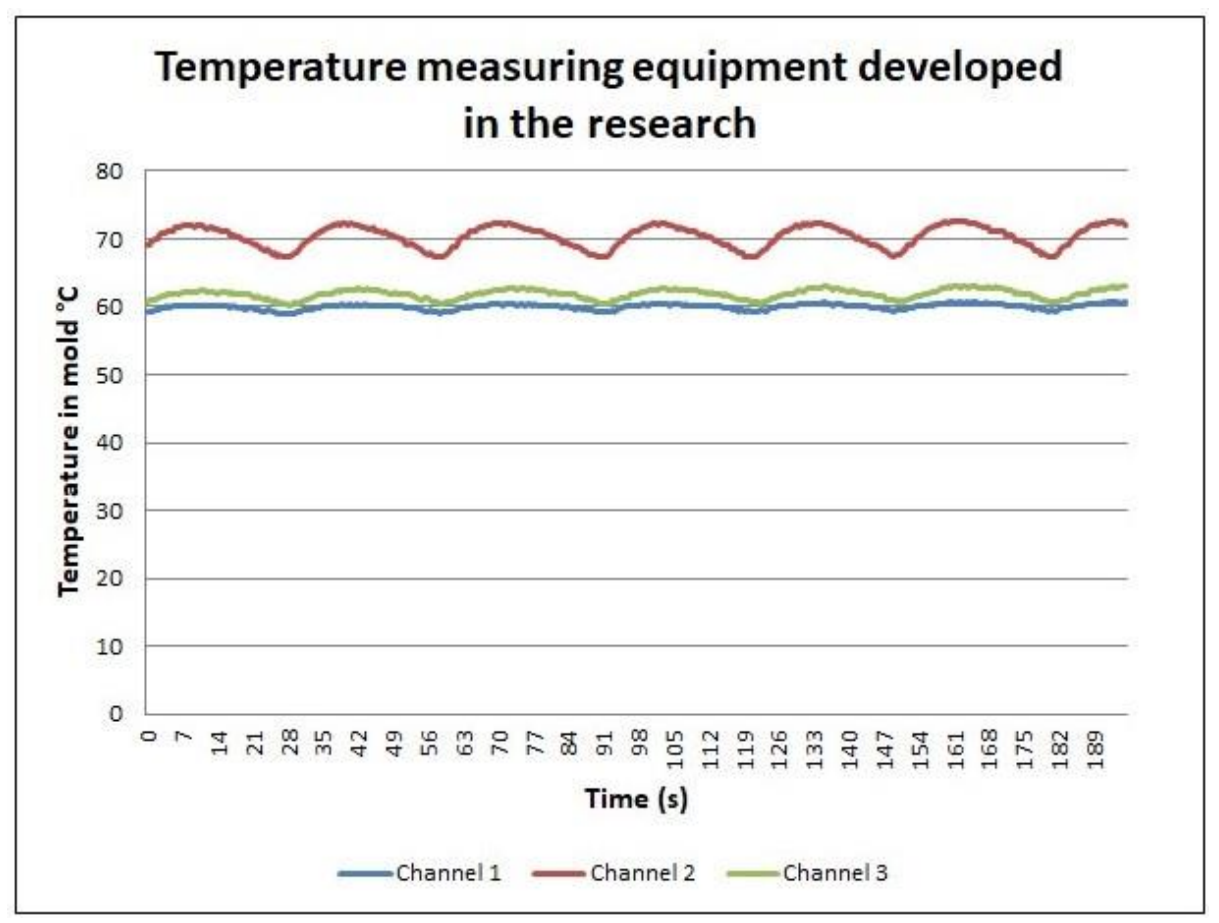

As a design feature, the temperature measurement equipment developed in the research has remote communication capability. Thus, in Figure 7 the WEB page used to initialize, finalize and verify in real time the measured temperatures in each of the thermocouples inserted in the mold. 
Figure 7. WEB page for operation and monitoring of temperature measuring equipment.

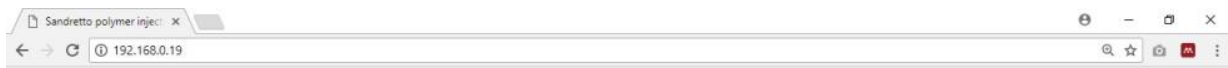

\section{ACQUISITION SYSTEM}

Start measurement Stop measurement

\section{TEMPERATURE IN THE MOLD}

Thermocouple $1-$ Temperature $=0.00{ }^{\circ} \mathrm{C}$

Thermocouple 2 - Temperature $=0.00{ }^{\circ} \mathrm{C}$

Thermocouple 3 - Temperature $=0.00{ }^{\circ} \mathrm{C}$

\section{Conclusion}

As a result of this research, a temperature measuring equipment was developed that uses as base of operation an open and modular microcontrolled platform, where it was possible to program input and output signals through programming, thus managing the connected temperature sensors in the three channels that the measuring.

As a characteristic of the Arduino platform, due to the fact that it is modular, using auxiliary modules, it was possible to meet all the stipulated objectives for the measuring equipment, being: realization of temperature measurement with equivalent quality to commercial equipment, data storage capacity, remote thermocouple temperature verification, data storage capacity on removable digital media, and the low cost for the construction of temperature measuring equipment, in the order of $\$ 250.00$.

In relation to the tests performed to verify the performance of the temperature measurement equipment developed in this research, different types of tests were carried out, both in the laboratory, with measured and controlled environmental conditions, as well as in the field, in the plastic materials manufacturing process.

In the test using the Sandretto brand polymer injection machine and the P20 steel mold, it was possible to verify the operation of the temperature measurement equipment in an industrial application, with the temperature measurement being carried out simultaneously in three channels of the measuring equipment, with the remote monitoring being used. As a result, a possible occurrence of noise or measurement problems was verified beyond the temperature in the mold, which could be caused by the type of environment to which the measuring equipment has undergone. However, no signs of noise or measurement inconsistencies were found in the temperature files.

As for the laboratory test, the tests were performed with the objective of verifying the errors of the temperature measurement equipment in relation to the systematic and random values of the measurements performed. As a complement, a statistical analysis of the test data was performed using the Minitab ${ }^{\circledR}$ statistical software to calculate the mean, standard deviation and confidence interval, $95 \%$ for the measured temperature measurements. 


\section{References}

[1] R. S. Figliola and D. E. Beasley, Theory And Design For Mechanical Measurements, 4th ed. New York: Wiley, 2005.

[2] A. Balbinot and V. J. Brusamarello, Instrumentação e Fundamentos de Medidas. Rio de Janeiro: LTC, 2011.

[3] P. Arpaia, E. De Matteis, and V. Inglese, "Software for measurement automation: A review of the state of the art," Measurement, vol. 66, pp. 10-25, Apr. 2015.

[4] P. Arpaia, "Instrumentation and measurement technologies for the CERN large Hadron Collider [Guest editorial]," IEEE Instrum. Meas. Mag., vol. 17, no. 1, pp. 4-7, 2014.

[5] C. G. Anzalone et al., "Open-Source Colorimeter," Sensors, vol. 13, no. 4, 2013.

[6] A. R. Al-Ali, "Internet of Things Role in the Renewable Energy Resources," Energy Procedia, vol. 100, pp. 34-38, 2016.

[7] F. Wortmann and K. Flüchter, "Internet of Things: Technology and Value Added," Bus. Inf. Syst. Eng., vol. 57, no. 3, pp. 221-224, 2015.

[8] P. P. Ray, "A survey on Internet of Things architectures," J. King Saud Univ. - Comput. Inf. Sci., 2016.

[9] Arduino, "Arduino-HomePage." [Online]. Available: https://www.arduino.cc/. [Accessed: 05Apr-2017].

[10] M. Fatehnia, S. Paran, S. Kish, and K. Tawfiq, "Automating double ring infiltrometer with an Arduino microcontroller," Geoderma, vol. 262, pp. 133-139, Jan. 2016.

[11] F. J. Mesas-Carrascosa, D. Verdú Santano, J. E. Meroño, M. Sánchez de la Orden, and A. García-Ferrer, "Open source hardware to monitor environmental parameters in precision agriculture," Biosyst. Eng., vol. 137, pp. 73-83, Sep. 2015.

[12] A. S. Ali, Z. Zanzinger, D. Debose, and B. Stephens, “Open Source Building Science Sensors (OSBSS): A low-cost Arduino-based platform for long-term indoor environmental data collection," Build. Environ., vol. 100, pp. 114-126, 2016.

[13] A. Kviesis and A. Zacepins, "System Architectures for Real-time Bee Colony Temperature Monitoring," Procedia Comput. Sci., vol. 43, pp. 86-94, 2015.

[14] M. Fezari, R. Rasras, and I. M. M. E. Emary, "Ambulatory Health Monitoring System Using Wireless Sensors Node," Procedia Comput. Sci., vol. 65, no. Iccmit, pp. 86-94, 2015.

[15] M. R. Laskar, R. Bhattacharjee, M. S. Giri, and P. Bhattacharya, "Weather Forecasting Using Arduino Based Cube-Sat," in Procedia Computer Science, 2016, vol. 89.

[16] B. Groener et al., "Preliminary Design of a Low-cost Greenhouse with Open Source Control Systems," in Procedia Engineering, 2015, vol. 107.

[17] E. C. Prima, S. Karim, S. Utari, R. Ramdani, E. R. R. Putri, and S. M. Darmawati, “Heat Transfer Lab Kit using Temperature Sensor based ArduinoTM for Educational Purpose," Procedia Eng., vol. 170, pp. 536-540, 2017.

[18] T. Georgieva, N. Paskova, B. Gaazi, G. Todorov, and P. Daskalov, "Design of Wireless Sensor Network for Monitoring of Soil Quality Parameters," Agric. Agric. Sci. Procedia, vol. 10, pp. 431-437, 2016.

[19] M. Gosai and S. N. Bhavsar, "Experimental Study on Temperature Measurement in Turning Operation of Hardened Steel (EN36)," Procedia Technol., vol. 23, pp. 311-318, 2016.

[20] L. Pocero, D. Amaxilatis, G. Mylonas, and I. Chatzigiannakis, “Open source IoT meter devices 
13 of 13

for smart and energy-efficient school buildings," HardwareX, vol. 1, pp. 54-67, 2017. 